\title{
Behavioral and transcriptome alterations in male and female mice with postnatal deletion of TrkB in dorsal striatal medium spiny neurons
}

Ellen M Unterwald ${ }^{1}$, Michelle E Page ${ }^{2}$, Timothy B Brown², Jonathan S Miller', Marta Ruiz ${ }^{3}$, Karen A Pescatore ${ }^{1}$, Baoji Xu ${ }^{4}$, Louis French Reichardt ${ }^{5}$, Joel Beverley ${ }^{6}$, Bin Tang ${ }^{7}$, Heinz Steiner ${ }^{6}$, Elizabeth A Thomas ${ }^{7}$ and Michelle E Ehrlich ${ }^{2,3^{*}}$

\begin{abstract}
Background: The high affinity tyrosine kinase receptor, TrkB, is the primary receptor for brain derived neurotrophic factor (BDNF) and plays an important role in development, maintenance and plasticity of the striatal output medium size spiny neuron. The striatal BDNF/TrkB system is thereby implicated in many physiologic and pathophysiologic processes, the latter including mood disorders, addiction, and Huntington's disease. We crossed a mouse harboring a transgene directing cre-recombinase expression primarily to postnatal, dorsal striatal medium spiny neurons, to a mouse containing a floxed TrkB allele (fB) mouse designed for deletion of TrkB to determine its role in the adult striatum.

Results: We found that there were sexually dimorphic alterations in behaviors in response to stressful situations and drugs of abuse. Significant sex and/or genotype differences were found in the forced swim test of depression-like behaviors, anxiety-like behaviors on the elevated plus maze, and cocaine conditioned reward. Microarray analysis of dorsal striatum revealed significant dysregulation in individual and groups of genes that may contribute to the observed behavioral responses and in some cases, represent previously unidentified downstream targets of TrkB.
\end{abstract}

Conclusions: The data point to a set of behaviors and changes in gene expression following postnatal deletion of TrkB in the dorsal striatum distinct from those in other brain regions.

Keywords: TrkB.FL, Medium spiny neuron, Dorsal striatum, BDNF, DARPP-32

Brain-derived neurotrophic factor (BDNF) and its high affinity tyrosine kinase receptor, TrkB, play important roles in development, maintenance and plasticity of the striatal output medium size spiny neuron (MSN). Eighty to ninety percent of the BDNF in the striatum is anterogradely transported from the cortex, and the remainder is derived from the substantia nigra [1]. All MSNs express TrkB, the primary receptor for BDNF, but TrkB is enriched in dopamine D2-receptor (D2R)-expressing MSNs relative

\footnotetext{
* Correspondence: michelle.ehrlich@mssm.edu

${ }^{2}$ Farber Institute for Neurosciences, Thomas Jefferson University, Philadelphia, PA 19107, USA

${ }^{3}$ Departments of Neurology and Pediatrics, Icahn School of Medicine at Mount Sinai, Annenberg 14-44, Box 1137, 1 Gustave L. Levy Place, New York, New York 10019, USA

Full list of author information is available at the end of the article
}

to D1R-expressing MSNs [2-4]. TrkB is encoded by the gene, Neurotrophic tyrosine kinase, receptor, type 2 (Ntrk2). There are two major TrkB isoforms, including the full-length TrkB.FL containing the tyrosine kinase domain, i.e. tk+, and a C-terminal truncated form, TrkB.T1, lacking the catalytic tyrosine kinase domain. TrkB.T1 is a dominant-negative receptor that inhibits TrkB.FL signaling, but has many other functions, including as a signal transducing molecule [5].

The striatal BDNF/TrkB system is implicated in physiologic and pathophysiologic processes, e.g. mood disorders and addiction, which present as primary diseases and as disorders associated with neurodegenerative diseases, including Alzheimer's, Huntington's and Parkinson's disease. In addition, the system is directly implicated in striatal 
dysfunction and degeneration in Huntington's disease. Thus, the BDNF/TrkB system is a potential therapeutic target in a myriad of clinical conditions. An emerging aspect of the study of this system is the disparate, and sometimes opposite, effects on behavior derived from its manipulation in different brain regions, e.g. hippocampus vs. ventral striatum [6]. Within the striatum, studies of mood disorders and addiction focus largely on the ventral portion, but evidence continues to accumulate supporting a role for the dorsal striatum in these pathologies. The dorsal striatum, including the caudate and putamen sub-regions, is an intrinsic part of the circuitry of mood disorders [7], and dorsal striatal dysfunction is particularly relevant in compulsive drug seeking [8] and gating of alcohol intake [9]. The dorsal striatum also obviously plays a key role in Huntington's and Parkinson's disease.

We sought to examine the role of the TrkB receptor in mature MSNs in adult male and female mice, with a focus on behavior and gene expression. Previous studies following constitutive and conditional deletion of the TrkB receptor in all MSNs or subtypes [2,4,10,11] were based largely on deletion during the prenatal period. In addition, in the prior studies, TrkB deletion was not restricted to MSNs. A limited number of studies utilizing viral-mediated Cre recombinase, overexpression of TrkB, or siRNA knockdown of TrkB in adult rodents have been published [12,13], but none has compared males to females. To this end, we used a mouse in which Cre-recombinase expression is delayed until the postnatal period, and in which within the forebrain, the transgene is restricted to MSNs [14]. We found sexually dimorphic changes in animal behaviors that are reflective of pathophysiology associated with human mood disorders and drug abuse. We also used a genome-wide assay of the TrkB-deleted dorsal striatal transcriptome to identify downstream TrkB targets which may be associated with alterations in behavior and to compare these alterations to those that occur following prenatal deletion of cortical BDNF.

\section{Results}

\section{Creation of D9 $\Delta$ TrkB mouse and assays of TrkB level}

We previously created a transgenic mouse (aka D9-Cre) using $9 \mathrm{~Kb}$ of the Ppp1r1b gene to drive expression of Cre-recombinase in postnatal striatal medium spiny neurons [14]. D9-Cre was crossed with a floxed $\operatorname{TrkB}$ mouse (aka $\mathrm{fB}$ ), which deletes the signal peptide of TrkB. Importantly, the $\mathrm{fB} / \mathrm{fB}$ homozygous mouse has a normal level of TrkB [2]. Homozygote $\mathrm{fB}$, heterozygote D9-Cre mice were used for this study, and we refer to them as $D 9 \Delta \operatorname{TrkB}$. Controls were $\mathrm{fB} / \mathrm{fB}$ only without any expression of cre recombinase. On western blotting of protein from the dorsal striatum, male and female $\mathrm{fB} / \mathrm{fB}$ mice had equal levels of TrkB.FL (Figure 1a, P >0.05, not significant). Using western blotting, RT-qPCR and in situ hybridization with full-length TrkB-specific primers, we found that TrkB mRNA and protein were decreased by $50 \%$ in the dorsal striatum in males and females, and by $25-40 \%$ in the ventral striatum/nucleus accumbens in $\mathrm{D} 9 \Delta \mathrm{TrkB}$ mice compared to $\mathrm{fB} / \mathrm{fB}$ controls. These data are consistent with our previous report showing that D9-Cre directs recombination in the majority of the dorsal MSNs, with a lower level of recombination in the ventral striatum [14]. The decrease in TrkB.T1 protein did not reach significance in D9 $\Delta$ trkB mice (Figure 1b). Of note, striatal interneurons express a higher level of $\operatorname{TrkB}$ than is found in MSNs, and glia express a high level of TrkB. T1 $[3,5,15]$. The D9-Cre transgene is not expressed in either interneurons or glia, and hence the remaining TrkB likely results from expression in these cell types, in addition to pre-synaptic TrkB receptors on glutamatergic terminals. Previous reports with early conditional deletion of TrkB using $D l \times 5 / 6$-Cre recombinase reported an almost complete deletion of both FL and T1 TrkB $[2,4]$, but the percent decreases using more selective Cre drivers or viral-mediated-Cre recombination were similar to that which we observed $[10,12]$.

\section{D9 $\Delta$ TrkB male and female mice have normal baseline motor behavior}

Each behavior assay was performed on a naïve cohort. Pan-neuronal, prenatal deletion of TrkB usually leads to early postnatal death, but the mice that survive for several weeks display circling, hind limb clasping, dystonic-like features, and ataxia. Selective early, prenatal striatal deletion leads to a failure of MSN development, and is also associated with hind-limb clasping and hypoactivity $[2,4]$. Life span and adult weight of $\mathrm{D} 9 \Delta \mathrm{TrkB}$ mice were normal and the mice were free of spontaneous motor abnormalities and hind limb clasping up to 24 months of age. Although females of both genotypes had higher activity counts than males, there were no genotypedependent differences in total activity, ambulatory activity or stereotypy in 6-month-old male and female $\mathrm{D} 9 \Delta \operatorname{TrkB}$ and $\mathrm{fB} / \mathrm{fB}$ mice (Figure $1 \mathrm{c}$ ). In addition, latency to fall on rotarod testing was unchanged in adult $\mathrm{D} 9 \Delta \operatorname{TrkB}$ mice indicating no effect of genotype on motor coordination (data not shown).

\section{D9 $\Delta$ TrkB male and female mice display genotype- and sex-dependent differences in depression- and anxiety-like behaviors}

Depressive- and anxiety-like behaviors were assayed in naive cohorts of 6-month-old male and female mice. The forced swim test was used to assess depression-like behavior [16]. Mice were placed individually into a cylinder of water for 6 minutes during which time activity was measured in terms of passive immobility or active swimming and climbing. In this test, increasing periods of immobility 

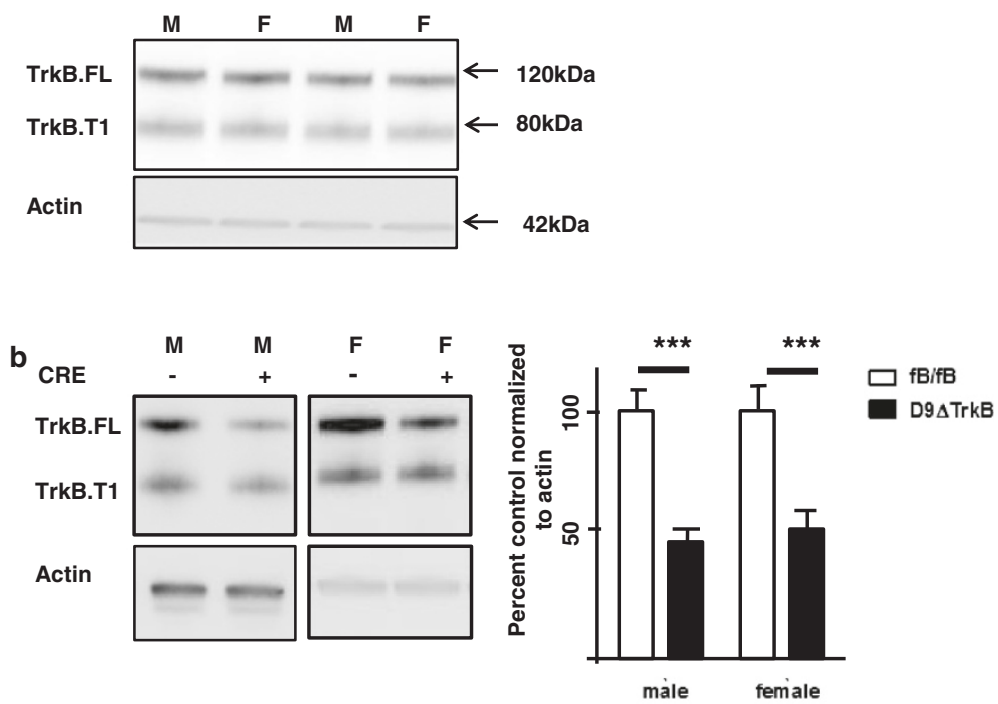

C

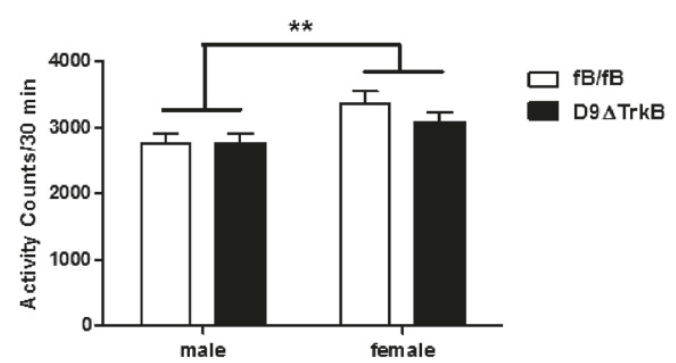

Figure 1 Baseline striatal TrkB level and locomotor activity in D94TrkB mice. (a) Baseline levels of striatal TrkB.FL and TrkB.T1 are equal in $\mathrm{fB} / \mathrm{fB}$ male and female mice. Densitometric values were normalized to actin. Blot is representative of $\mathrm{N}=6, \mathrm{p}>0.05$ (t-test). (b) Relative to fB/fB, D9 $\Delta$ TrkB male and female mice demonstrate approximately a 50\% decrease in striatal TrkB.FL ( $N=3-4,{ }^{* * *} \mathrm{P}<0.005, t$-test). There is a trend towards a small decrease in TrkB.T1 ( $N=3, P=0.06$, t-test). Densitometric values were normalized to actin, and fB/fB levels were arbitrarily set to equal 1. (c) Down-regulation of striatal MSN TrkB.FL does not alter baseline total activity, but there is a genotype-independent increase in activity in female mice relative to males ( $\mathrm{N}=8-12 /$ group, ${ }^{* *} \mathrm{P}<0.01$ two-way ANOVA for sex factor).

are associated with a depression-like phenotype, whereas clinically useful antidepressants reduce immobility [16]. Results of the forced swim test demonstrated that male D9 $\Delta$ TrkB mice had lower immobility scores versus male $\mathrm{fB} / \mathrm{fB}$. One-way ANOVA revealed a significant effect of genotype for the males $(\mathrm{F}[1,26]=8.52 ; \mathrm{P}<0.01$; Figure $2 \mathrm{a})$, indicating an anti-depressive phenotype, but no difference for females.

To determine the effects of deletion of striatal MSN TrkB on anxiety, mice were tested in the elevated plus maze [17]. Two-way ANOVA revealed a significant sex by genotype interaction $(\mathrm{F}(1,29)=4.279, \mathrm{P}<0.05$; Figure $2 \mathrm{~b})$. $\mathrm{D} 9 \Delta \operatorname{TrkB}$ males displayed lower anxiety-like behavior on the elevated plus maze as shown by significantly greater time spent in the open arms compared with control $\mathrm{fB} / \mathrm{fB}$ male mice $(\mathrm{P}<0.05$; Figure $2 \mathrm{~b} ;)$. $\mathrm{D} 9 \Delta$ TrkB females did not show this effect as there was no significant difference between genotypes in the time spent in the open arms of the elevated plus maze for the females $(P>0.50)$.

\section{Cocaine conditioned reward}

Conditioned place preference was used to measure the rewarding effects of cocaine $(10 \mathrm{mg} / \mathrm{kg}$, ip) in $\mathrm{D} 9 \Delta \mathrm{TrkB}$ versus $\mathrm{fB} / \mathrm{fB}$ adult male and female mice. Two-way ANOVA revealed a significant sex by genotype interaction $(\mathrm{F}(1,26)=4.935, \mathrm{P}<0.05$; Figure $2 \mathrm{c})$. Male mice showed a significant place preference for the cocaine-paired environment with no significant differences between genotypes. Females, however, showed a significant effect of genotype. Cocaine produced a larger place preference in $\mathrm{D} 9 \Delta \mathrm{TrkB}$ females than in $\mathrm{fB} / \mathrm{fB}$ female mice $(P<0.05)$. Further, $f B / f B$ males showed a greater preference for the cocaine-paired environment than $\mathrm{fB} / \mathrm{fB}$ females $(P<0.05)$. These results suggest an increase in 


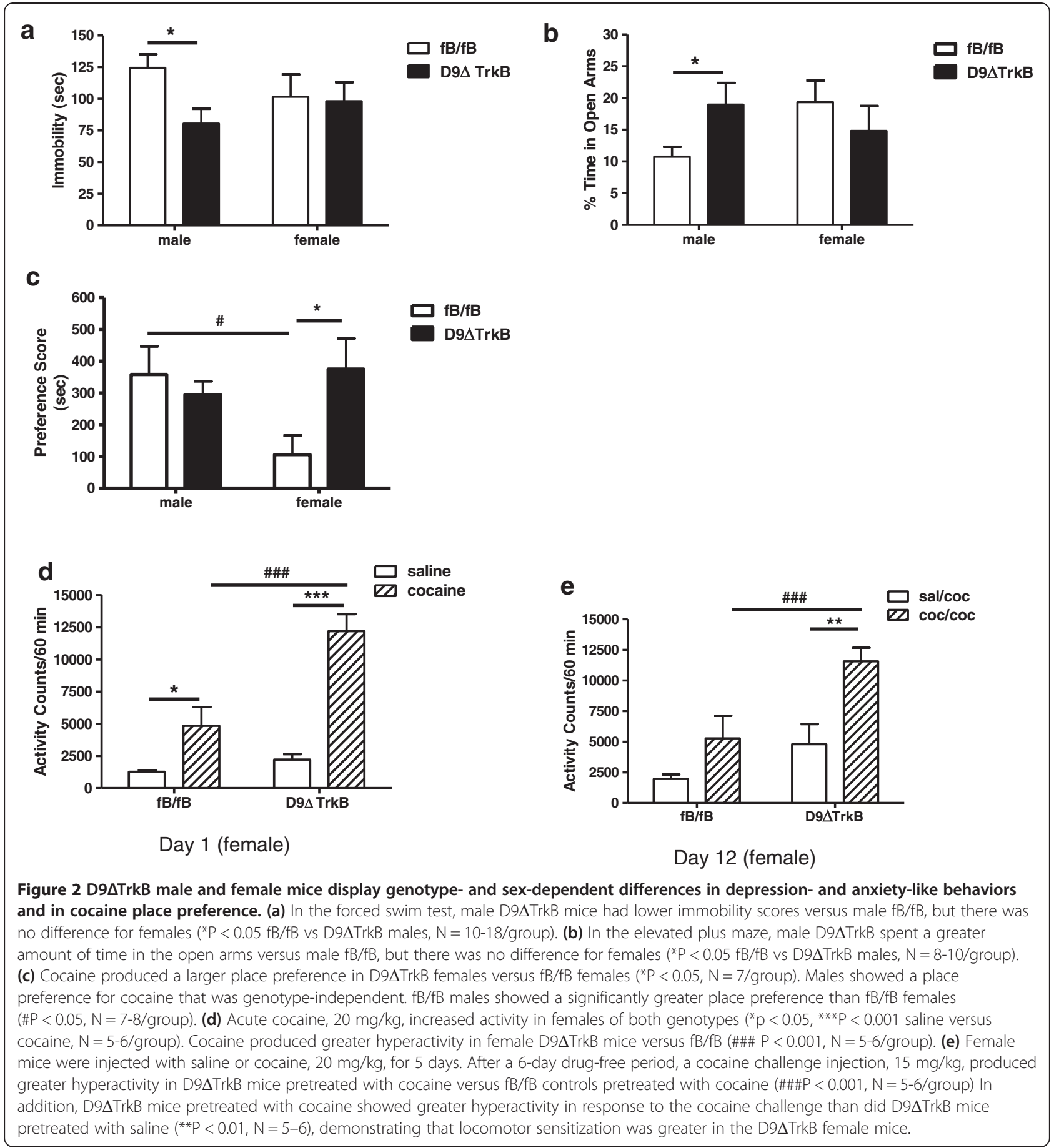

cocaine reward upon TrkB deletion in the striatum selectively in female mice.

Locomotor responses to acute and repeated administration of cocaine in female $f B / f B$ and $D 9 \Delta T$ TkB mice

Based on genotype- and sex-specific results in the cocaine place preference assay, we investigated the response to acute and repeated administration of cocaine in female mice to analyze acute activity and stereotypy responses to cocaine, and to determine if $\mathrm{D} 9 \Delta \mathrm{TrkB}$ female mice sensitized to the motor-stimulating effects of repeated administration of cocaine. Figure $2 \mathrm{~d}$ shows total activity counts of female $D 9 \Delta \operatorname{TrkB}$ and $\mathrm{fB} / \mathrm{fB}$ mice following the first saline or cocaine $(20 \mathrm{mg} / \mathrm{kg}$, ip) injection. Two-way ANOVA revealed a significant effect of genotype $(\mathrm{F}(1,18)=16.96$, $\mathrm{P}=0.0006)$, treatment $(\mathrm{F}(1,18)=45.03, \mathrm{P}<0.0001)$, and interaction $(\mathrm{F}(1,18)=10.06, \mathrm{P}=0.0053)$. Cocaine produced greater hyperactivity in female $\mathrm{D} 9 \Delta \mathrm{TrkB}$ mice as compared 
with female $\mathrm{fB} / \mathrm{fB}$ controls $(\mathrm{P}<0.001)$. When activity was separated into ambulatory and stereotypy responses, D9 $\Delta$ TrkB female mice showed higher levels of both ambulatory and stereotypic activity following a cocaine injection $(\mathrm{P}<0.01$ and $\mathrm{P}<0.001$, respectively; data not shown).

Next, female mice were injected with saline or cocaine, $20 \mathrm{~m} / \mathrm{kg}$ ip, once daily for 5 days, which was followed by a 6-day drug-free period. On day 12, all mice were challenged with a cocaine injection $(15 \mathrm{mg} / \mathrm{kg}$ ip) and activity recorded to test for the development of sensitization. Two-way ANOVA showed a significant effect of genotype $(\mathrm{F}(1,18)=12.68, \mathrm{P}=0.0022)$ and treatment $(\mathrm{F}(1,18)=15.42$, $\mathrm{P}=0.001$ ) for total activity (Figure 2e), D9 $\Delta$ TrkB female mice, but not control $\mathrm{fB} / \mathrm{fB}$ females, showed behavioral sensitization as evidenced by significantly greater hyperactivity following the cocaine challenge on Day 12 in $\mathrm{D} 9 \Delta \operatorname{TrkB}$ pretreated with cocaine than in $\mathrm{D} 9 \Delta \operatorname{TrkB}$ pretreated with saline $(\mathrm{P}<0.01)$. In addition, a genotype effect was found in that $\mathrm{D} 9 \Delta \mathrm{TrkB}$ mice pretreated with cocaine showed greater hyperactivity in response to the cocaine challenge as compared with control mice pretreated with cocaine $(\mathrm{P}<0.001)$. There were significant genotype effects for both ambulatory $(\mathrm{P}<0.05)$ and stereotypic activity $(\mathrm{P}<0.01)$ with $\mathrm{D} 9 \Delta \mathrm{TrkB}$ mice being the high responders in both cases (data not shown). These results demonstrate a hyperactive phenotype of the D $9 \Delta \operatorname{TrkB}$ female mice in response to acute and repeated cocaine administration.

\section{Alterations in gene expression in dorsal striatum in D9 $\Delta$ TrkB mice}

Prenatal, conditional deletion of cortical BDNF using Emx1-cre mediated recombination results in a myriad of changes in the transcriptome [18] and changes in expression of selected genes have been identified following prenatal deletion of TrkB throughout the striatum or in specific MSN subtypes [2,4,10]. Genome-wide assay of the transcriptome following deletion of striatal TrkB at any age or in specific MSN subtypes has not previously been reported, and we reasoned that chronic down-regulation of $\operatorname{TrkB}$ in the mature MSN would alter the transcription of multiple genes. In situ hybridization of Ntrk2, Penk, Tacr1, Ppp1r1b and Pdyn mRNAs demonstrated distinct patterns of regulation in male D $9 \Delta \mathrm{TrkB}$ mice and the data are summarized in Table 1. Figure 3a schematically shows dorsal striatal sub-regions that were analyzed at the mid-level of the striatum, the level at which all effects were maximal. In the sub-regions, Ntrk2 mRNA was decreased from 40-60\%, with an overall decrease of $51 \%$ (fB/fB $19.7+/-1,7$ vs D9 $\Delta$ TrkB $10.0+/-1.2$, arbitrary units, $\mathrm{P}=0.005)$. Penk mRNA was decreased from $30-45 \%$ with an overall decrease of $38 \%$ (Figure $3 \mathrm{~b}$; $\mathrm{fB} / \mathrm{fB} 70.0+/-4.1$ vs $\mathrm{D} 9 \Delta$ TrkB $43.6+/-1.3, \mathrm{P}<0.001)$. Ppp1r1b were decreased in the dorsal striatum, with a

\begin{tabular}{|c|c|c|}
\hline $\begin{array}{l}\text { Gene ID } \\
\text { (mRNA) }\end{array}$ & $\begin{array}{l}\text { Dorsal striatum } \\
\text { (caudate-putamen) }\end{array}$ & $\begin{array}{l}\text { Ventral striatum } \\
\text { (nucleus accumbens) }\end{array}$ \\
\hline Ntrk2 & (-) $51 \%, P<0.01$ & (-) 40\%, P $<0.05$ \\
\hline Penk & $(-) 38 \%, P<0.001$ & (-) $18 \%, P<0.05$ \\
\hline Ppp1r1b (lateral) & (-) 15\%, P $<0.01$ & No change \\
\hline Tacr1 (lateral) & (-) 20\%, $P<0.05$ & No change \\
\hline Pdyn & (+) $30 \%, P<0.05$ & No change \\
\hline
\end{tabular}

medial-lateral gradient, maximal in the lateral region of the middle level ( $\mathrm{fB} / \mathrm{fB} 44.0+/-0.5$ vs $\mathrm{D} 9 \Delta \mathrm{TrkB} 37.6+/-1.0$, $\mathrm{P}=0.004)$. In the same region, Tacr 1 was decreased by $20 \%$ (fB/fB $61.7+/-3.7$ vs. D9 $\Delta$ TrkB 50.0+/-2.4, $\mathrm{P}=0.04$ ). $P d y n$ was increased in $\mathrm{D} 9 \Delta \mathrm{TrkB}$ relative to $\mathrm{fB} / \mathrm{fB}$, significant only on the middle level ( $\mathrm{fB} / \mathrm{fB} 19.2+/-1.1$ vs $\mathrm{D} 9 \Delta \operatorname{TrkB}$ $26.1+/-2.1 ; \mathrm{P}<0.05)$. In the nucleus accumbens at $+5.2 \mathrm{~mm}$ rostral to the interaural line, Ntrk2 was decreased by $40 \%$ $(\mathrm{fB} / \mathrm{fB} 26.2+/-3.6$ vs $\mathrm{D} 9 \Delta \operatorname{TrkB} 15.4+/-1.0, \mathrm{P}=0.02)$. A lower level of Cre-mediated recombination in the nucleus accumbens was most obvious when assaying downstream targets of TrkB deletion, as Penk was decreased by only $18 \%$ (fB/fB $75.6+/-3.8$ vs $\mathrm{D} 9 \Delta \operatorname{TrkB} 61.7+/-2.5, \mathrm{P}=0.02$ ), and Tacr1, Ppp1r1b and Pdyn were unaltered in the nucleus accumbens.

RT-qPCR assays were then performed with samples derived from the dorsal striatum of male mice (Figure 3c). Since the entire dorsal striatum was dissected for this analysis, it is important to note that sub-region-specific alterations within the striatum were possibly masked. For example, although Ppp1r1b/DARPP-32 is markedly up-regulated by BDNF during development [19] and was decreased in $\mathrm{D} 9 \Delta \mathrm{TrkB}$ dorsolateral striatum as measured by in situ hybridization, it was unchanged as measured by RT-qPCR. Given that TrkB is enriched in dopamine receptor type 2 (D2R) MSNs relative to dopamine receptor type 1 (D1R) MSNs [2], we performed a screen of transcripts that distinguish between MSN subtypes, e.g. direct pathway D1R neurons, indirect pathway D2R neurons, and markers of patch and matrix MSNs (Figure 3c). We found that levels of $\operatorname{Drd} 1$ and $\operatorname{Drd} 2$ mRNAs were unchanged in dorsal striatum of male D9 $\Delta$ TrkB mice. The A2ar/adenosine receptor type 2 mRNA, which co-localizes with D2R and not with D1R, and subunits of the NMDA receptor were also unchanged. Although morphometric studies were not the focus of this study, the $\mathrm{D} 9 \Delta \operatorname{TrkB}$ striatum appeared smaller and the lateral ventricles larger than in $\mathrm{fB} / \mathrm{fB}$ control mice. Normal A2ar mRNA level suggests that death of $\mathrm{D} 2 \mathrm{R}$ neurons is not excessive, but as BDNF is required for postnatal growth of MSN dendritic complexity and spine density [20], such deficits could contribute both to a decrease 
a

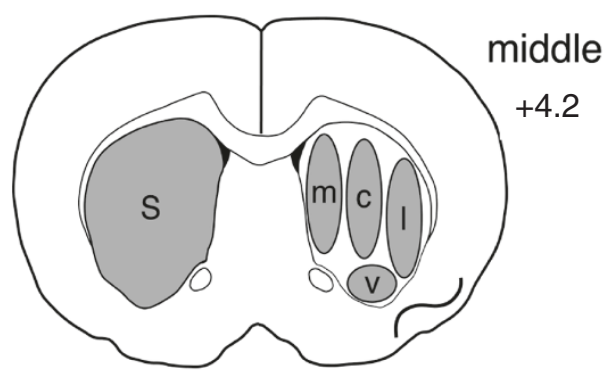

b

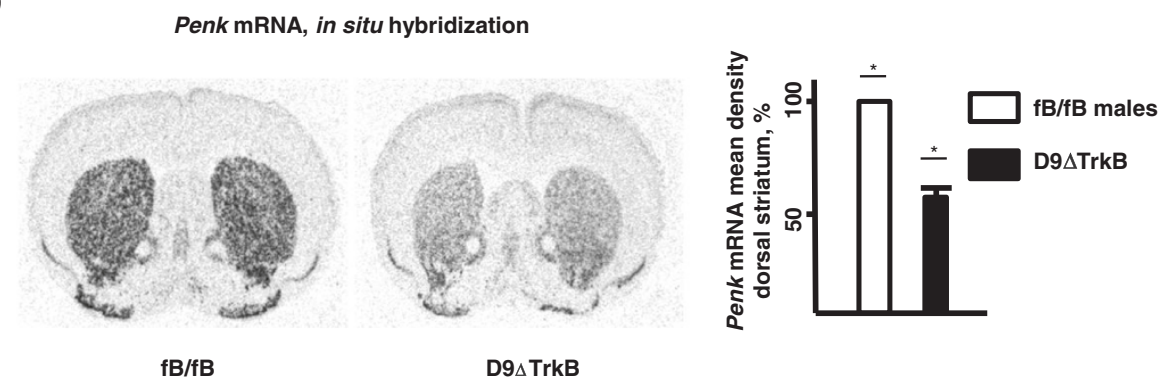

C

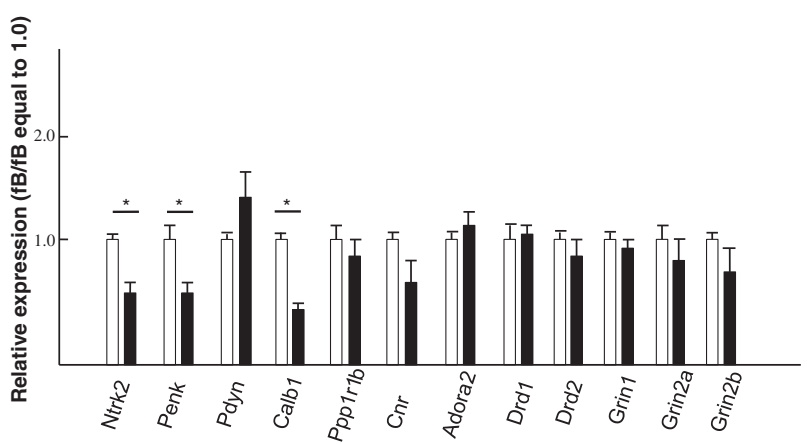

Figure 3 Down-regulation of striatal MSN TrkB leads to specific alterations in expression of MSN-enriched transcripts in male mice. (a) Diagram of dorsal striatal regions (middle level, $4.2 \mathrm{~mm}$ rostral to the interaural line) used for quantitation of results of in situ hybridization of Ntrk2, Penk, Tacr1, Ppp1r1b and Pdyn mRNAs. S= striatum, $\mathrm{m}=$ medial, $\mathrm{c}=$ central, I = lateral, $\mathrm{v}=$ ventral. (b) Densitometry of representative autoradiograms of Penk mRNA in situ hybridization on mid-level striatal sections shows a 40\% reduction in preproenkephalin mRNA level ( $\mathrm{N}=3$ $f B / f B, N=4 D 9 \Delta T r k B, P<0.01$, t-test). (c) RT-qPCR was performed on samples derived from the dorsal striatum of male mice ( $N=4 / g e n o t y p e)$, confirming a significant decrease in Ntrk2 and Penk mRNAs in D9 $\Delta$ TrkB mice versus $\mathrm{fB} / \mathrm{fB}$ mice ( ${ }^{*} \mathrm{P}<0.01$, t-test) and demonstrating greater than $50 \%$ decrease in Calb1 mRNA ( $\mathrm{P}<0.01$, t-test).

in striatal size and striatal dysfunction. Further work is required to determine whether this apparent size difference is significant, and if so, its origin. Consistent with the in situ hybridization data, Penk, also enriched in D2R indirect pathway MSNs, was markedly decreased, as was Calb1/calbindin, which is enriched in the matrix compartment. Also consistent with the in situ hybridization, Pdyn, enriched in D1R MSNs and the striosome/patch compartment [21], strongly trended upwards $(\mathrm{P}=0.07)$. Cnr1, or cannabinoid receptor 1 , is present in both D1R and D2R neurons and strongly trended downwards $(P=0.07)$. These data suggest that genes expressed in MSNs and regulated by TrkB are not relegated to a specific MSN subtype.
We next performed a microarray analysis of baseline gene expression in female dorsal striatum of $\mathrm{fB} / \mathrm{fB}$ and $\mathrm{D} 9 \Delta \operatorname{TrkB}$ mice $(\mathrm{N}=4 /$ genotype). There were 1749 transcripts that were altered at the $\mathrm{P}<0.05$ level of significance (Additional file 1: Table S1). Importantly, there was only one discrepancy for the transcripts assayed in Figure 3c, as Calb1 mRNA was unchanged by microarray. Calb1 mRNA was, however, decreased in female D9 $\Delta$ TrkB striatum by over $50 \%$ when assayed by RT-qPCR (Figure $4 \mathrm{a}$ ). We focused on the 325 transcripts dysregulated in D9 $\Delta \mathrm{TrkB}$ mice at $P$ value less than 0.005 (Additional file 1: Table S1), in order to identify candidate genes potentially relevant to behavioral alterations described herein. Of these, 93 were up-regulated following MSN TrkB deletion, and 260 were 


\section{a}

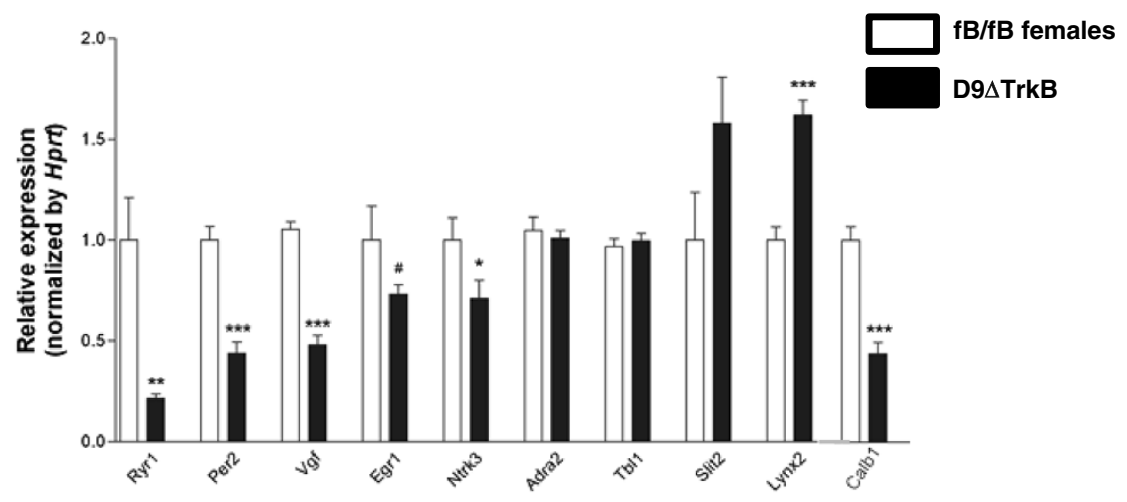

b

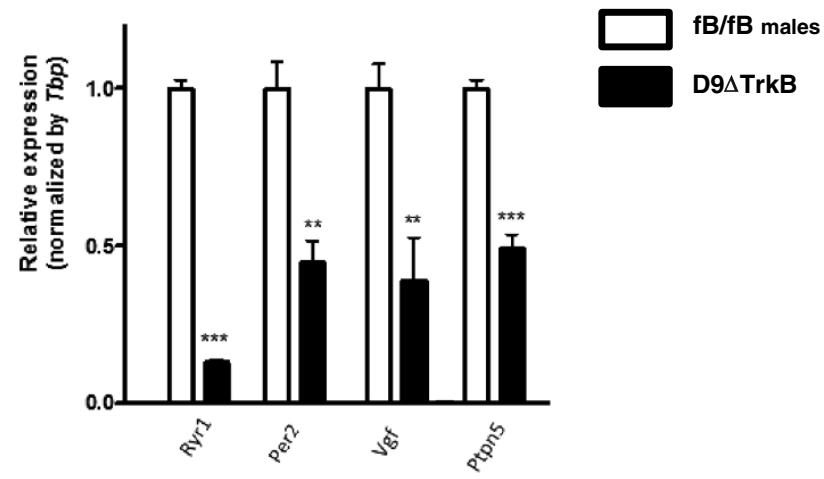

C

BDNF KO $0.05(n=3098) \quad$ D9 $\Delta$ TrkB CRE $0.005(n=325)$

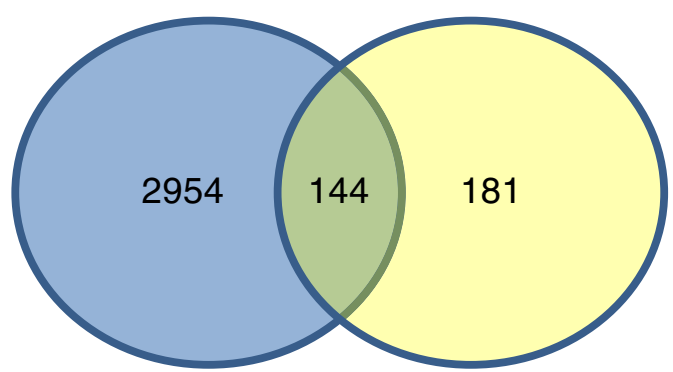

Figure 4 Microarray analysis of dorsal striatal samples from female D9ATrkB mice reveals widespread alterations in gene expression (see Table 2). (a) RT-qPCR assay of Ryr1, Slit2, Egr1, Ntrk3, Vgf, Per2, and Lynx2 mRNAs validated the results of the microarray analysis, whereas assay of Adra2 mRNA did not show a difference between genotypes ( $N=4 /$ genotype; ${ }^{*} P<0.05,{ }^{* *} P<0.01$, $\left.{ }^{* * *} P<0.001\right)$. (b) RT-qPCR assay of Ryr1, Per2, Ptpn5 and Vgf mRNAs in striatal samples from male mice $(N=4$ /genotype) showed reductions in transcripts similar to those observed in samples from females ( ${ }^{* *} \mathrm{P}<0.01$, ${ }^{* *} \mathrm{P}<0.001$ ). (c) Venn diagram illustrating that of the top 325 genes with mRNA levels altered at the $P<0.005$ level in D9 4 TrkB mice, only 144 were altered in BDNF-null mice (from [18]) at the least stringent level of significance, $\mathrm{P}<0.05$.

down-regulated. Included amongst those that we validated in female mice by RT-qPCR are Vgf, Egr1, Lynx2, Per2, Ryr1 and Slit2 (Figure 4a), chosen in large part for their known or hypothesized associations with behaviors assayed in this study and/or synaptic plasticity. Of note, several of these have not previously been associated with the BDNF/ TrkB signal transduction system, e.g. Per2. Ntrk3/TrkC was significantly down-regulated, indicating that not only does this neurotrophin receptor not compensate for the knockdown of $N t r k 2 / \operatorname{TrkB}$, but that it is a direct or indirect downstream target of Ntrk2 and may contribute to the alterations following deletion of MSN TrkB.

We interrogated the microarray data to identify pathways and functional classes over-represented in the list of altered transcripts. Using GOEAST and DAVID at both $\mathrm{P}<0.005$ and 0.01 levels of significance, enrichment and 
gene clusters were found in the following Gene Ontology (GO) classifications: metal ion transport, voltage gated ion channel activity, and metal ion and cation membrane transporter activity. These pathways and molecules are associated with intracellular calcium regulation and signal transduction, and some are known to be required for BNDF activity [22]. Amongst them is the aforementioned Calb1 and Ryr1, and also Calb2, Hpcal4, Cacng5, and Homer1, the latter known to be associated with BDNF activity and plasticity [23].

We next used Ingenuity Systems Pathways Analysis to examine canonical pathways that were significantly correlated with genes differentially expressed in the striatum of D9 $\Delta$ Trkb mice. Top pathways included Protein kinase A signaling, G-protein signaling, CXCR4 signaling and RAR activation (Table 2). The Protein kinase A signaling pathway contained Ptpn5/STEP, a striatal-enriched gene known to be associated with responses to drugs of abuse and stress [24], and not previously identified as being regulated by BDNF/TrkB. In addition, there were alterations in several genes encoding members of the cAMP-mediated signaling pathway, e.g. Rgs 2 and $A d c y 1$, and other signal transduction pathways, including CREB and ErbB2-ErbB3 (Table 2).

Transcripts for multiple immediate early genes and other transcription factors or co-regulators were found to be significantly altered in $\mathrm{D} 9 \Delta \mathrm{TrkB}$ mice, implying that the dysregulated genes are likely comprised of direct and indirect targets of TrkB signaling. These include several immediate early genes and transcription factors associated with plasticity and responses to drugs of abuse, e.g. Arc, Egr1, 2 and 4, and known to be up-regulated by BDNF and/or required for its downstream gene regulation $[25,26]$. Others include Dusp6, Pou3f1, Klf5, Calcoco1, and Ppargc1 $\alpha$. Interestingly, Ppargc1 $\alpha$ is up-regulated, contrary to what would be anticipated by studies in Huntington disease models in which cortical BDNF, striatal TrkB, and Ppargc1 $\alpha$ are all down-regulated (reviewed in [27]).

An obvious question is whether sexual dimorphism in gene regulation may account for sex-dependent behavioral differences in $\mathrm{D} 9 \Delta \mathrm{TrkB}$ mice. Although we did not perform a second microarray analysis on male mice, we did assay levels of several potentially relevant transcripts that we had assayed in female mice either by qPCR or as part of the microarray analysis, including Ptpn5 (striatum-enriched protein tyrosine phosphatase), Ryr1(ryanodine receptor 1), $V g f$ (nerve growth factor inducible), and Per2 (periodic circadian clock 2). All four transcripts were altered in the same direction and magnitude as in the female mice (Figure 4b).

\section{Discussion}

This is the first report to directly address the effects of postnatal knockdown of MSN TrkB throughout the striatum, but with a focus on the dorsal portion, i.e. caudate-putamen. Previous studies utilized mice expressing the $D l x 5 / 6-$, Drd1- and Drd2-cre recombinase drivers, and thereby deleted TrkB in the prenatal period in both dorsal and ventral striatum and in cell types other than MSNs. Viral-mediated manipulation of FL or T1 TrkB in the adult mouse has focused on the ventral striatum. By using a promoter that fortuitously directs expression of Cre-recombinase to postnatal MSNs, the mice studied herein are unlikely to have marked developmental deficits and their attendant molecular compensations. We found that 1) D9 $\Delta$ TrkB mice have normal lifespan and baseline behavior; 2) there is a sexually dimorphic effect on performance in the forced swim test and elevated plus maze, detectable only in $\mathrm{D} 9 \Delta \mathrm{TrkB}$ males; 3 ) the response to cocaine in $\mathrm{D} 9 \Delta \operatorname{TrkB}$ mice is also sexually dimorphic, with an increased genotype-dependent preference for cocaine in females; 4) female D9 $\Delta \mathrm{TrkB}$ mice show increased locomotor sensitization to chronic cocaine relative to $\mathrm{fB} / \mathrm{fB}$ controls; and 5) there is a marked effect of $\operatorname{TrkB}$ down-regulation on baseline gene expression in the dorsal striatum.

Sexual dimorphism in the response to physiological and behavioral stress, and the direct relationship of this response to the development of mental illness, may be organizational and/or activational (reviewed in $[28,29]$. The caudate-putamen is a sexually dimorphic brain region, based on sex-specific differences in size and in the number of gonadal hormone receptors [30]. In our study, female mice were group housed, with $\mathrm{D} 9 \Delta \mathrm{TrkB}$ and $\mathrm{fB} / \mathrm{fB}$ mice in the same cages. Female mice were not ovariectomized, and estrus cycle was not determined prior to or after testing. It is highly unlikely therefore, that the observed sexual dimorphism was dependent on circulating sex steroid, suggesting organizational effects independent of circulating hormone levels. This hypothesis is being tested in ongoing experiments. Our study contributes to the emerging literature on sexual dimorphism in the neurotrophic system. There are interactions between sex steroid hormones and BDNF in many species, organs, and brain regions, which may modulate transcription, translation, and/or strength of signal transduction of BDNF and TrkB [31-35]. Our data imply that adult males may be more sensitive to a decrease in striatal TrkB level, but perhaps surprisingly, the changes were not detrimental per se, and may even be considered beneficial. Data from studies of whole brain and/or hippocampus [36-38] largely show that a decrease in the level of BDNF, and by extension TrkB, generally leads to an increase in depressive- and anxiety-related behaviors or in females, a lower threshold for stress-induced anhedonic behavior. An important exception in the literature is a strong trend to a decrease in anxiety-related behavior in female mice following forebrain deletion of BDNF [37]. On the other hand, BDNF in the nucleus accumbens is pro-depressant and an experimental decrease in BDNF or an increase in TrkB.T1 in the nucleus accumbens is 
Table 2 Top canonical pathways associated with TrkB deletion in mouse striatal MSNs

\begin{tabular}{|c|c|c|c|}
\hline Canonical pathway: & -log (p-value): & Ratio: & Molecules: \\
\hline Thrombin signaling & $2.69 \mathrm{E}+00$ & 5.34E-02 & $\begin{array}{l}\text { ARHGEF10, MPRIP, GATA1, RHOT2, ADCY1, GNB5, CAMK1G, HRAS, } \\
\text { PRKCH, GNG7, PRKCB }\end{array}$ \\
\hline Protein kinase A signaling & $2.63 \mathrm{E}+00$ & $4.28 \mathrm{E}-02$ & $\begin{array}{l}\text { SHH, PTPN7, PTPRE, SMAD3, DUSP6, GNB5, PTPN5, TCF7, GNG7, PTEN, } \\
\text { ADD3, ADCY1, SMAD4, RYR1, PRKCH, CDC16, PRKCB }\end{array}$ \\
\hline Galpha(i) signaling & $2.44 \mathrm{E}+00$ & $6.06 \mathrm{E}-02$ & GRM8, NPY1R, ADCY1, GNB5, HRAS, ADRA2C, STAT3, GNG7 \\
\hline Prolactin signaling & $2.39 \mathrm{E}+00$ & $7.50 \mathrm{E}-02$ & HRAS, PRKCH, STAT3, SOCS5, TCF7, PRKCB \\
\hline CXCR4 signaling & $2.36 \mathrm{E}+00$ & $5.36 \mathrm{E}-02$ & EGR1, RHOT2, ADCY1, GNB5, HRAS, PRKCH, ELMO1, GNG7, PRKCB \\
\hline Glutamate receptor signaling & $2.18 \mathrm{E}+00$ & $7.25 \mathrm{E}-02$ & GRM8, SLC1A1, HOMER1, GNG7, GRIK1 \\
\hline Galpha(s) signaling & $2.11 \mathrm{E}+00$ & 5.79E-02 & RGS2, ADD3, ADCY1, GNB5, RYR1, HTR6, GNG7 \\
\hline Cell cycle: G1/S checkpoint regulation & $2.06 \mathrm{E}+00$ & $7.58 \mathrm{E}-02$ & PA2G4, HDAC8, SMAD3, SMAD4, CDKN1B \\
\hline Beta-adrenergic signaling & $2.04 \mathrm{E}+00$ & $5.71 \mathrm{E}-02$ & ADCY1, GNB5, HRAS, PRKCH, GNG7, PRKCB \\
\hline Phospholipase C signaling & $2.04 \mathrm{E}+00$ & 4.23E-02 & $\begin{array}{l}\text { ARHGEF10, MPRIP, HDAC8, RHOT2, ADCY1, GNB5, ITGA5, } \\
\text { HRAS, PRKCH, GNG7, PRKCB }\end{array}$ \\
\hline Neuregulin signaling & $2.00 E+00$ & $5.88 \mathrm{E}-02$ & ITGA5, HRAS, PRKCH, CDKN1B, PTEN, PRKCB \\
\hline G Beta gamma signaling & $2.00 \mathrm{E}+00$ & $5.13 \mathrm{E}-02$ & ADCY1, GNB5, HRAS, PRKCH, GNG7, PRKCB \\
\hline RAR activation & $1.98 \mathrm{E}+00$ & 4.76E-02 & SMAD3, ADCY1, SMAD4, PRKCH, ERCC2, PTEN, PPARGC1A, RBP4, PRKCB \\
\hline Virus entry via endocytic pathways & $1.97 \mathrm{E}+00$ & $6.06 \mathrm{E}-02$ & ITGA5, TFRC, HRAS, PRKCH, CXADR, PRKCB \\
\hline Chronic myeloid leukemia signaling & $1.86 \mathrm{E}+00$ & $5.71 \mathrm{E}-02$ & PA2G4, HDAC8, SMAD3, SMAD4, HRAS, CDKN1B \\
\hline Glioma signaling & $1.84 \mathrm{E}+00$ & $5.36 \mathrm{E}-02$ & PA2G4, CAMK1G, HRAS, PRKCH, PTEN, PRKCB \\
\hline Axonal guidance signaling & $1.77 \mathrm{E}+00$ & $3.42 \mathrm{E}-02$ & $\begin{array}{l}\text { SHH, GNB5, HRAS, SEMA6B, ITGA5, FZD1, SLIT2, GIT1, GNG7, NTNG1, } \\
\text { SEMA3A, SUFU, BAIAP2, ABLIM2, PRKCH, PRKCB }\end{array}$ \\
\hline Breast cancer regulation by stathmin 1 & $1.73 E+00$ & 4.35E-02 & ARHGEF10, ADCY1, GNB5, CAMK1G, HRAS, PRKCH, CDKN1B, GNG7, PRKCB \\
\hline Molecular mechanisms of cancer & $1.60 \mathrm{E}+00$ & $3.44 \mathrm{E}-02$ & $\begin{array}{l}\text { SHH, PA2G4, SMAD3, RHOT2, HRAS, FZD1, ARHGEF10, SUFU, ADCY1, } \\
\text { SMAD4, PRKCH, CDKN1B, PRKCB }\end{array}$ \\
\hline Renin-angiotensin signaling & $1.60 \mathrm{E}+00$ & 4.80E-02 & ADCY1, HRAS, SHC3, PRKCH, STAT3, PRKCB \\
\hline CREB signaling in neurons & $1.56 \mathrm{E}+00$ & $3.94 \mathrm{E}-02$ & GRM8, ADCY1, GNB5, HRAS, PRKCH, GNG7, GRIK1, PRKCB \\
\hline Androgen signaling & $1.55 \mathrm{E}+00$ & 4.17E-02 & SMAD3, GNB5, PRKCH, ERCC2, GNG7, PRKCB \\
\hline ErbB2-ErbB3 signaling & $1.51 E+00$ & 6.67E-02 & HRAS, STAT3, CDKN1B, PTEN \\
\hline Calcium signaling & $1.48 \mathrm{E}+00$ & 3.79E-02 & TNNT1, HDAC8, CAMK1G, TPM2, RYR1, TRPC4, CASQ2, GRIK1 \\
\hline 14-3-3-mediated signaling & $1.45 \mathrm{E}+00$ & 4.96E-02 & STK11, TSC2, HRAS, PRKCH, CDKN1B, PRKCB \\
\hline P2Y purigenic receptor signaling pathway & $1.42 \mathrm{E}+00$ & 4.35E-02 & ADCY1, GNB5, HRAS, PRKCH, GNG7, PRKCB \\
\hline PTEN signaling & $1.42 \mathrm{E}+00$ & 4.44E-02 & INPP5F, FLT1, ITGA5, HRAS, CDKN1B, PTEN \\
\hline IL-8 signaling & $1.41 E+00$ & $3.90 \mathrm{E}-02$ & FLT1, RHOT2, GNB5, HRAS, PRKCH, IRAK3, GNG7, PRKCB \\
\hline CAMP-mediated signaling & $1.41 \mathrm{E}+00$ & $4.02 \mathrm{E}-02$ & RGS2, GRM8, NPY1R, DUSP6, ADCY1, CAMK1G, ADRA2C, HTR6, STAT3 \\
\hline
\end{tabular}

Microarray data were analyzed through the use of IPA (Ingenuity ${ }^{\oplus}$ Systems, www.ingenuity.com).

The p-value was calculated using the right-tailed Fisher Exact Test, considering the number of molecules participating in a given pathway and the total number of molecules associated with that pathway in Ingenuity's knowledge base.

"anti-depressant" in male mice [6]. A decrease in depressiveand anxiety-related behaviors in male mice following striatal TrkB knockdown is also consistent with a recent report of similar effects following administration of a TrkB antagonist [39]. Thus, albeit highly speculative, a decrease in TrkB activity in the striatum appears to "override" a decrease in the hippocampus, and knockdown in the dorsal striatum is required for an effect on anxiety-related behaviors, which are not altered by knockdown of the BDNF/ TrkB system restricted to the nucleus accumbens, or to D1R or D2R MSNs. It is therefore important to note that in studies utilizing forebrain deletion of BDNF [37,38], the amount of BDNF transported from the ventral tegmental area to the nucleus accumbens may not have been altered. Together, these data encourage further investigation into the role of the dorsal striatum in depression and anxiety, and the apparent differences that arise from whole brain and region-specific manipulation of BDNF or TrkB.

The question of the regional and neuronal subtype origins of behavioral changes is also relevant to the responses to cocaine observed in this study. It remains 
difficult to parse out exclusive functions for the ventral and dorsal striatum, but the reward mechanism as measured by preference for cocaine in the conditioned place preference paradigm is largely attributed to the ventral striatum whereas acute locomotor activity and locomotor sensitization to cocaine are primarily mediated by the dorsal striatum [40-43]. The dorsal striatum, however, is strongly implicated in reward mechanisms based on habit learning theories of addiction [8], as particularly demonstrated in models of an escalation in cocaine seeking that implicate BDNF signal transduction $[44,45]$. Deletion of TrkB in dorsal and ventral striatal D1R MSNs results in increased preference for cocaine and increased sensitization in male mice, whereas deletion in D2R MSNs (and presumably some interneurons) has opposite effects [10]. A decrease in accumbal TrkB in both D1R and D2R MSNs reduces cocaine reward [12,13]. Prenatal deletion of TrkB in Penk-containing MSNs results in baseline hyperlocomotion and an enhanced locomotor response to cocaine in males, but sensitization and cocaine preference were not assayed in this study [11]. Our data imply that in females, the role of the D1R MSNs overrides that of the D2R MSNs when TrkB is down-regulated in both MSN subtypes during the postnatal period. They may also suggest that accumbal TrkB is a limiting factor in previously reported responses, as we saw a lesser and more variable decrease in $\operatorname{TrkB}$ in this region. These data therefore reinforce the relevance of the dorsal striatum and the difficulty in attributing behaviors specifically to the dorsal or ventral regions [42], and highlight the need for increased attention to female models of disease.

We identified many gene expression abnormalities that were associated with TrkB down-regulation in MSNs. Of the 325 genes identified in the present study with transcript levels altered at $\mathrm{P}<0.005$, only 144 of these transcripts have been reported to be altered in BDNF-null mice at the least stringent level of significance, $\mathrm{P}<0.05$ [18] (Figure 4c). These data suggest that the MSN TrkB receptor is mediating a distinct subset of behavioral and physiological effects elicited by BDNF in the striatum. In addition, it is possible that prenatal disruption of striatal BDNF/TrkB signaling may produce more widespread alterations of the transcriptome than postnatal down-regulation of BDNF/TrkB signaling, although expression of BDNF in the cortex is low in the prenatal period. Finally, it is possible that the broader disruption of the striatal transcriptome following deletion of BDNF represents other cell types and/or noncell-autonomous effects on MSN transcription. Although not directly comparable, it is interesting to note that of the 20 transcripts with the greatest fold-change in our microarray analysis, only one is altered in the nucleus accumbens following cre-mediated deletion of BDNF in the adult ventral tegmental area [46], and several transcripts with lower fold-change, e.g. Per2 and Egr3, are altered in opposite directions.

It is tempting, but premature, to assign changes in behavior that we measured in the $\mathrm{D} 9 \Delta \operatorname{TrkB}$ mice to the observed altered gene expression patterns, i.e. metal ion transport or second messenger signaling; however it is possible that chronic, baseline alterations may have different effects than drug-induced alterations. It is also likely that changes in individual genes may antagonize each other, and so effects of transcripts that were studied in isolation may not be as pertinent when they are altered as part of a wider effect on the transcriptome. For example, Per2 is not a known target of $\mathrm{BDNF} / \mathrm{TrkB}$, and an isolated reduction in Per2 is predicted to increase cocaine preference [47], but only females displayed a genotype-dependent difference in cocaine preference. Differences in regional effects are also important. Strikingly, a decrease in Vgf peptide in the hippocampus is strongly associated with pro-depressant effects [48], yet male D $9 \Delta \operatorname{TrkB}$ mice display antidepressant activity despite a $60 \%$ decrease in Vgf in the striatum. It thus also remains to be determined whether alterations in the transcriptome are sexually dimorphic, given that our gene expression comparison between sexes was limited. The striatum displays a higher number of sex-biased genes than do the hippocampus and cortex, including in the expression of Ntrk3 and Pdyn $[49,50]$. Protein kinase A signal transduction is also altered in a sexually dimorphic manner after self-administration of cocaine, an effect that could be synergistic with chronic changes in expression of proteins whose activity is regulated by phosphorylation, e.g. Ppp1r1b/DARPP-32 [51]. Finally, the list of striatal genes dysregulated following deletion of TrkB includes genes that are expressed at sexually dimorphic levels in other brain regions, but remain to be studied in the striatum, e.g. the aforementioned Per2. Thus, the microarray data provide important and novel leads for targeted study of genetic and epigenetic regulation of sexual dimorphism in the striatum, particularly as related to the BDNF/TrkB system.

\section{Conclusions}

In summary, knockdown/deletion of adult striatal, MSN TrkB results in alterations of behavior and gene expression which differ qualitatively and quantitatively from those that occur following prenatal deletion. Changes in behaviors in response to stressful situations or drugs are sexually dimorphic, but it remains to be determined whether the same is true for prenatal deletion and gene expression. The data encourage further investigation into the role of the dorsal striatum and individual TrkB targets in these behaviors. 


\section{Methods \\ Genotyping}

Mice were group housed, given ad libitum access to food and water, and housed under a 12-hour light/dark cycle. All animal procedures were conducted in accordance with the National Institute of Health Guidelines for the Care and Use of Experimental Animals and were approved by the Institutional Animal Care and Use Committee at the Icahn School of Medicine at Mount Sinai. Mice with a floxed TrkB allele (fB) [2] and the D9-Cre recombinase mouse [14] have been previously described. Both strains were in the C57BL/6 J background. Tail DNA was prepared from three week old mice. To distinguish between floxed TrkB heterozygote and homozygote mice, the sequence of the PCR primers were as follows: Trkb-n2: ATG TCG CCC TGG CTG AAG TG; Trkb-c8: ACT GAC ATC CGT AAG CCA GT; Trkb-c7: GAT GAT TTC TAG CCT TTT CTG G. TrkB-n2 and Trkb-c8 amplify a 369 bp product from the wild type TrkB allele, whereas Trkb-n2 and Trkb-c7 amplify a 245 bp product from the $\mathrm{fB}$ allele. Cre recombinase is detected using a second set of sequence-specific primers [14]. D9-Cre/fB was crossed with $\mathrm{fB} / \mathrm{fB}$, which has a normal level of TrkB in the homozygous state [2]. We refer to $\mathrm{fB} / \mathrm{fB}$ mice expressing D9-cre as D9 $\Delta$ TrkB. Six to ten month old mice were used for this study.

\section{Western blotting}

Protein levels were measured by western blot analysis of protein extracted from regionally dissected brain tissue. Soluble protein was extracted from tissue in $20 \mathrm{mM}$ Hepes (pH 7.6), $150 \mathrm{mM} \mathrm{NaCl}, 0.5 \mathrm{mM}$ EDTA, and 0.5\% Triton X-100, supplemented with 1X Complete protease inhibitor cocktail (Roche Diagnostics GmbH, Mannheim, Germany), $1 \mathrm{mM}$ PMSF, $50 \mathrm{mM} \mathrm{NaF}$, and $1 \mathrm{mM} \mathrm{Na-orthovanadate.}$ Protein levels in the extracts were determined using the Bio-Rad DC Protein Assay. Antibodies used included antiTrkB (1:1000) (BD Biosciences, Sparks, MD, USA) and anti- $\beta$-actin (1:1000, Sigma, St. Louis, MO). Blots were developed and visualized using the Fujifilm LAS-4000 Plus Gel Documentation System and Reader (Fujifilm Holdings Corporation, Tokyo, Japan). Densitometric values were obtained using Multi Gauge software for analysis (Fujifilm Lifesciences, Tokyo, Japan).

\section{Forced Swimming Test (FST)}

Mice were subjected to the swim chamber after an acclimation period ( 2 hours) in the staging area outside of the testing room. Mice were placed individually into a glass cylinder (46 cm tall x $21 \mathrm{~cm}$ in diameter) filled with water $\left(23-25^{\circ} \mathrm{C}\right.$ water) to a depth of $15 \mathrm{~cm}$ for six minutes. The depth is deep enough so that mice cannot support themselves by placing their paws on the base of the cylinder. A cylinder of this diameter was used because the larger swimming area has been reported to increase the predictive validity of the mouse FST [52]. The experiment was videotaped from above and scored later by a rater blind to the genotype. The total duration of immobility during the last $4 \mathrm{~min}$ of the test was determined from videotapes.

\section{Elevated plus maze}

The elevated plus maze was used to measure anxiety-like behaviors. The mouse elevated plus maze (San Diego Instruments, San Diego, CA) consists of four equal-sized runways (12 inches long and 2 inches wide) laid-out in the shape of a plus sign and elevated off the ground by 15 inches. Two of the arms are enclosed by solid walls, 6 inches high on the long sides (closed arms), whereas the other two arms have no sides (open arms). A ledge (1/8 inch high) is present around the perimeter of the open arms of the maze. Test room lighting was adjusted such that open arm light levels were w200 lux and closed arm light levels were w160 lux. On test day, mice were acclimated to the room for 60 minutes prior to testing. Each mouse was placed on the center maze and their behavior was recorded for 10 minutes. The videotapes were scored at a later time by a person blind to the genotype. The number of entries into the open and closed arms and the time spent in each arm were measured. An entry was counted when the superior portion of the mouse including the head and neck, the shoulders, the forelimbs and forepaws, and the thoracic region moved into an arm.

\section{Locomotor activity}

Activity was measured using the Digiscan D-Micropro automated activity monitoring system (Accuscan, Inc., Columbus, $\mathrm{OH}$ ). The activity monitors consist of transparent plastic boxes $(45 \times 20 \times 20 \mathrm{~cm})$ set inside metal frames that are equipped with 16 infrared light emitters and detectors. The number of photocell beam breaks is recorded by a computer interface in 5 minute bins. Mice were placed into the activity monitors and activity was recorded for 30 minutes during acclimation to the chambers. After 30 minutes, cocaine $(20 \mathrm{mg} / \mathrm{kg}$ ip) or saline ( $3 \mathrm{ml} / \mathrm{kg}$ ip) was administered and mice were immediately returned to the activity monitors for 60 additional minutes of activity measurement. This was repeated once daily for 5 days. After a 6-day drug-free period, all mice were injected with cocaine $(15 \mathrm{mg} / \mathrm{kg}$ ip) and activity was measured as before in order to test for behavioral sensitization.

\section{Conditioned place preference}

Conditioned place preference was performed using a two compartment apparatus. The two compartments were of equal size but one had solid black walls and a smooth floor whereas the other compartment had black and white vertical striped walls and a rough floor. There 
was a removable wall between the two compartments of the apparatus. Mice were placed in the apparatus with free access to both compartments in a 30 minute pretest session. Time in each compartment was measured. Mice were conditioned for 30 minutes once daily for 4 days. On days 1 and 3, mice were injected with cocaine (10 mg/kg ip) and confined to one compartment. On days 2 and 4, mice were injected with saline ( $3 \mathrm{ml} / \mathrm{kg}$ ip) and confined to the other compartment in a counterbalanced design. The test session occurred 24 hours after the last conditioning session and lasted 30 minutes. During the test session, mice were placed into the apparatus with the wall between the compartments removed, identical to the pretest, and time spent in each compartment recorded. Preference scores are reported as time in the cocaine-paired compartment after conditioning minus time in the same compartment prior to conditioning in seconds.

\section{In situ hybridization}

Briefly [53], the mice were killed with $\mathrm{CO}_{2}$, and their brains were rapidly removed and frozen in isopentane cooled on dry ice. Brains were stored at $-20^{\circ} \mathrm{C}$ until cryostat sectioning. Coronal sections $(12 \mu \mathrm{m})$ were thaw-mounted onto glass slides (Superfrost/Plus; Daigger, Wheeling, IL, USA), dried on a slide warmer and stored at $-20^{\circ} \mathrm{C}$. Tissue sections were fixed in $4 \%$ paraformaldehyde $/ 0.9 \%$ saline for $10 \mathrm{~min}$ at room temperature, incubated in a fresh solution of $0.25 \%$ acetic anhydride in $0.1 \mathrm{M}$ triethanolamine/ $0.9 \%$ saline ( $\mathrm{pH}$ 8.0) for $10 \mathrm{~min}$, dehydrated, defatted for $2 X 5 \mathrm{~min}$ in chloroform, rehydrated, and air-dried. The slides were then stored at $-30^{\circ} \mathrm{C}$ until hybridization. Oligonucleotide probes (48-mers; Life Technologies, Rockville, MD, USA) were labeled with [35S]-dATP. The probes had the following sequence: for Tacr1/substance P, complementary to bases 20-67, GenBank accession no. M68909; Penk/ enkephalin, bases 304-351, M13227; Pdyn/dynorphin, bases 807-854, AF026537; Ntrk2/TrkB, bases 733-780, NM 008745; Ppp1r1b/DARPP-32, bases 1253-1300, BC031129. Striatal gene expression was determined in the nucleus accumbens (total area, at $\sim 5.2 \mathrm{~mm}$ rostral to the interaural line [54]; and in the mid-level striatum (total area and medial, central, lateral and ventral sectors; $4.2 \mathrm{~mm}$ rostral to the interaural line; Figure 3a). Gene expression was measured by densitometry (NIH Image; Wayne Rasband, NIMH) on film autoradiograms.

\section{Statistics}

Statistical analysis was conducted using GraphPad software (GraphPad Software, La Jolla, CA). In the case of comparison between genotypes, unpaired two-tailed Student t-test was used. One-way ANOVA or two- way ANOVA with sex and genotype or drug and genotype factors were used to analyze the behavioral data. Bonferroni post-hoc comparisons were used with significant ANOVAs. Unpaired t-test was used to analyze western blot, in situ hybridization and RT-qPCR data. Results were considered significant when $\mathrm{P}<0.05$.

\section{Microarray analysis}

Total RNA was extracted from the striatum of $\mathrm{fB} / \mathrm{fB}$ and D9 $\Delta$ TrkB transgenic mice using the Nucleospin RNA kit (BD Biosciences, San Jose, CA). RNA quantity was assessed with Nanodrop (Nanodrop Technologies) and quality with the Agilent Bioanalyzer (Agilent Technologies). Total RNA (200 ng) was amplified, biotinylated and hybridized on Illumina Mouse_8_V2 Beadchips, querying the expression of $\sim 22,000$ Refseq transcripts, as per manufacturer's protocol. Slides were scanned using Illumina BeadStation and signal extracted using Illumina BeadStudio software (Illumina, San Diego CA). Raw data was analyzed as previously described using Bioconductor packages. Quality assessment was performed looking at the inter-array Pearson correlation and clustering based on top variant genes was used to assess overall data coherence. Contrast analysis of differential expression was performed using the 'limma' package [55]. After linear model fitting, a Bayesian estimate of differential expression was calculated. Data analysis was aimed at identifying transcriptional changes in the $\mathrm{D} 9 \Delta \mathrm{TrkB}$ compared to $\mathrm{fB} / \mathrm{fB}$ mice using different uncorrected $\mathrm{p}$-value cut-offs ranging from $\mathrm{p}<0.001$ to $\mathrm{p}<0.05$.

\section{Pathway analyses}

Gene Ontology (GO) terms were identified using the Database for Annotation, Visualization and Integrated Discovery (DAVID) (http://david.abcc.ncifcrf.gov/) to understand the potential biological relevance of differentially expressed genes. Canonical pathway analysis was performed using Ingenuity Systems Pathway Analysis (http://www.ingenuity.com).

\section{Additional file}

Additional file 1: Table S1. Genes differentially expressed in striatum of D9 $\Delta$ TrkB mice at $P<0.05$.

\section{Competing interests}

The authors declare that there is no conflict of interest.

\section{Authors' contributions}

EMU, MEP, TBB, EAT, HS and MEE conceived and designed the experiments, performed experiments, reviewed and interpreted primary data, and were involved in drafting and editing the manuscript. BX and LFR contributed reagents and edited the manuscript. JSM, KAP, JB, MR, and BT designed and performed behavior, in situ hybridization or molecular genetic experiments, interpreted primary data and approved the final manuscript. All authors read and approved the final manuscript.

\section{Acknowledgements}

Sources of support include DA022422 (MEE and EMU), T32 DA007237 (EMU), P30 DA013429 (EMU) and DA011261 (HS). We acknowledge the technical assistance of Lauren Harper, Pierrette Andre, Loren Khan-Vaughan, and Justine Bonet. 


\section{Disclosure}

Drs. Ehrlich, Unterwald, Thomas, Heinz, Xu and Reichardt were funded by the National Institutes of Health $(\mathrm{NIH})$.

\section{Author details}

'Department of Pharmacology and Center for Substance Abuse Research, Temple University School of Medicine, Philadelphia, PA 19140, USA. ${ }^{2}$ Farber Institute for Neurosciences, Thomas Jefferson University, Philadelphia, PA 19107, USA. ${ }^{3}$ Departments of Neurology and Pediatrics, Icahn School of Medicine at Mount Sinai, Annenberg 14-44, Box 1137, 1 Gustave L. Levy Place, New York, New York 10019, USA. ${ }^{4}$ Department of Pharmacology, Georgetown University Medical Center, Washington, DC 20057, USA. ${ }^{5}$ Department of Physiology, University of California, San Francisco, CA 94158, USA. ${ }^{6}$ Department of Cellular and Molecular Pharmacology, The Chicago Medical School, Rosalind Franklin University of Medicine and Science, North Chicago, IL, USA. ${ }^{7}$ Department of Molecular Biology, The Scripps Research Institute, La Jolla, CA 92037, USA.

Received: 28 November 2013 Accepted: 19 December 2013

Published: 26 December 2013

\section{References}

1. Altar CA, Cai N, Bliven T, Juhasz M, Conner JM, Acheson AL, Lindsay RM, Wiegand SJ: Anterograde transport of brain-derived neurotrophic factor and its role in the brain. Nature 1997, 389:856-860.

2. Baydyuk M, Russell T, Liao GY, Zang K, An JJ, Reichardt LF, Xu B: TrkB receptor controls striatal formation by regulating the number of newborn striatal neurons. Proc Natl Acad Sci U S A 2011, 108:1669-1674.

3. Costantini LC, Feinstein SC, Radeke MJ, Snyder-Keller A: Compartmental expression of TrkB receptor protein in the developing striatum. Neuroscience 1999, 89:505-513.

4. Li Y, Yui D, Luikart BW, McKay RM, Li Y, Rubenstein JL, Parada LF Conditional ablation of brain-derived neurotrophic factor-TrkB signaling impairs striatal neuron development. Proc Natl Acad Sci U S A 2012, 109:15491-15496.

5. Fenner BM: Truncated TrkB: beyond a dominant negative receptor. Cytokine Growth Factor Rev 2012, 23:15-24.

6. Nestler EJ, Carlezon WA Jr: The mesolimbic dopamine reward circuit in depression. Biol Psychiatry 2006, 59:1151-1159.

7. Price JL, Drevets WC: Neural circuits underlying the pathophysiology of mood disorders. Trends Cogn Sci 2012, 16:61-71.

8. Lesscher HM, Vanderschuren L: Compulsive drug use and its neural substrates. Rev Neurosci 2012, 18:1-15.

9. Jeanblanc J, He DY, Carnicella S, Kharazia V, Janak PH, Ron D: Endogenous BDNF in the dorsolateral striatum gates alcohol drinking. J Neurosci 2009, 29:13494-13502.

10. Lobo MK, Covington HE 3rd, Chaudhury D, Friedman AK, Sun H, Damez-Werno D, Dietz DM, Zaman S, Koo JW, Kennedy PJ, Mouzon E, Mogri M, Neve RL, Deisseroth K, Han MH, Nestler EJ: Cell type-specific loss of BDNF signaling mimics optogenetic control of cocaine reward. Science 2010, 330:385-390.

11. Besusso D, Geibel M, Kramer D, Schneider T, Pendolino V, Picconi B, Calabresi P, Bannerman DM, Minichiello L: BDNF-TrkB signaling in striatopallidal neurons controls inhibition of locomotor behavior. Nat Commun 2031, 2013:4.

12. Graham DL, Krishnan V, Larson EB, Graham A, Edwards S, Bachtell RK, Simmons D, Gent LM, Berton O, Bolanos CA, DiLeone RJ, Parada LF, Nestler EJ, Self DW: Tropomyosin-related kinase B in the mesolimbic dopamine system: region-specific effects on cocaine reward. Biol Psychiatry 2009, 65:696-701.

13. Bahi A, Boyer F, Chandrasekar V, Dreyer JL: Role of accumbens BDNF and TrkB in cocaine-induced psychomotor sensitization, conditioned-place preference, and reinstatement in rats. Psychopharmacology (Berl) 2008, 199:169-182.

14. Bogush Al, McCarthy LE, Tian C, Olm V, Gieringer T, Ivkovic S, Ehrlich ME: DARPP-32 genomic fragments drive Cre expression in postnatal striatum. Genesis 2005, 42:37-46.

15. Wang Y, Hagel C, Hamel W, Müller S, Kluwe L, Westphal M: Trk A, B, and C are commonly expressed in human astrocytes and astrocytic gliomas but not by human oligodendrocytes and oligodendroglioma. Acta Neuropathol 1998, 96:357-364.
16. Castagné V, Moser P, Porsolt RD: Behavioral assessment of antidepressant activity. In Rodents in Methods of Behavior Analysis in Neuroscience. Edited by Buccafusco JJ. Boca Raton: CRC Press; 2009:140-151.

17. Pellow S, Chopin P, File SE, Briley M: Validation of open:closed arm entries in an elevated plus-maze as a measure of anxiety in the rat. J Neurosci Methods 1985, 14:149-167.

18. Strand AD, Baquet $Z C$, Aragaki AK, Holmans P, Yang L, Cleren C, Beal MF, Jones $L$, Kooperberg C, Olson JM, Jones KR: Expression profiling of Huntington's disease models suggests that brain-derived neurotrophic factor depletion plays a major role in striatal degeneration. J Neurosci 2007, 27:11758-11768.

19. Ivkovic S, Ehrlich ME: Expression of the striatal DARPP-32/ARPP-21 phenotype in GABAergic neurons requires neurotrophins in vivo and in vitro. J Neurosci 1999, 19:5409-5419.

20. Rauskolb S, Zagrebelsky M, Dreznjak A, Deogracias R, Matsumoto T, Wiese S, Erne B, Sendtner M, Schaeren-Wiemers N, Korte M, Barde YA: Global deprivation of brain-derived neurotrophic factor in the CNS reveals an area-specific requirement for dendritic growth. J Neurosci 2010, 30:1739-1749.

21. Gong S, Zheng C, Doughty ML, Losos K, Didkovsky N, Schambra UB, Nowak NJ, Joyner A, Leblanc G, Hatten ME, Heintz N: A gene expression atlas of the central nervous system based on bacterial artificial chromosomes. Nature 2003, 425:917-925.

22. Amaral MD, Pozzo-Miller $\mathrm{L}$ : Intracellular $\mathrm{Ca} 2+$ stores and $\mathrm{Ca} 2+$ influx are both required for BDNF to rapidly increase quantal vesicular transmitter release. Neural Plast 2012, 2012:203536.

23. Mahan AL, Mou L, Shah N, Hu JH, Worley PF, Ressler KJ: Epigenetic modulation of Homer1a transcription regulation in amygdala and hippocampus with pavlovian fear conditioning. J Neurosci 2012, 32:4651-4659.

24. Goebel-Goody SM, Baum M, Paspalas CD, Fernandez SM, Carty NC, Kurup P, Lombroso PJ: Therapeutic implications for striatal-enriched protein tyrosine phosphatase (STEP) in neuropsychiatric disorders. Pharmacol Rev 2012, 64:65-87.

25. Valjent E, Aubier B, Corbillé AG, Brami-Cherrier K, Caboche J, Topilko P, Girault JA Hervé D: Plasticity-associated gene Krox24/Zif268 is required for long-lasting behavioral effects of cocaine. J Neurosci 2006, 26:4956-4960.

26. Keilani S, Chandwani S, Dolios G, Bogush A, Beck H, Hatzopoulos AK, Rao GN, Thomas EA, Wang R, Ehrlich ME: Egr-1 induces DARPP-32 expression in striatal medium spiny neurons via a conserved intragenic element. J Neurosci 2012, 32:6808-6818.

27. Ehrlich ME: Huntington's disease and the striatal medium spiny neuron: cell-autonomous and non-cell-autonomous mechanisms of disease. Neurotherapeutics 2012, 9:270-284.

28. Bonthius PJ, Cox KH, Searcy BT, Kumar P, Tobet S, Rissman EF: Of mice and rats: key species variations in the sexual differentiation of brain and behavior. Front Neuroendocrinol 2010, 31:341-358.

29. Viveros MP, Mendrek A, Paus T, López-Rodríguez AB, Marco EM, Yehuda R, Cohen H, Lehrner A, Wagner EJ: A comparative, developmental, and clinical perspective of neurobehavioral sexual dimorphisms. Front Neurosci 2012, 6:84.

30. Goldstein JM, Seidman LJ, Horton NJ, Makris N, Kennedy DN, Caviness VS Jr, Faraone SV, Tsuang MT: Normal sexual dimorphism of the adult human brain assessed by in vivo magnetic resonance imaging. Cereb Cortex 2001, 11:490-497.

31. Carrer HF, Cambiasso MJ: Sexual differentiation of the brain: genes, estrogen, and neurotrophic factors. Cell Mol Neurobiol 2002, 22:479-500.

32. Harte-Hargrove LC, Maclusky NJ, Scharfman HE: BDNF-estrogen interactions in the hippocampal mossy fiber pathway: implications for normal brain function and disease. Neuroscience 2013, 239:46-66.

33. Hill RA, van den Buuse M: Sex-dependent and region-specific changes in TrkB signaling in BDNF heterozygous mice. Brain Res 2011, 1384:51-60

34. Liu Y, Rutlin M, Huang S, Barrick CA, Wang F, Jones KR, Tessarollo L, Ginty DD: Sexually dimorphic BDNF signaling directs sensory innervation of the mammary gland. Science 2012, 338:1357-1360.

35. Tang YP, Wade J: 17ß-estradiol regulates the sexually dimorphic expression of BDNF and TrkB proteins in the song system of juvenile zebra finches. PLoS One 2012, 7:e43687.

36. Krishnan V, Nestler EJ: Linking molecules to mood: new insight into the biology of depression. Am J Psychiatry 2010, 167:1305-1320.

37. Autry AE, Adachi M, Cheng P, Monteggia LM: Gender-specific impact of brain-derived neurotrophic factor signaling on stress-induced depression-like behavior. Biol Psychiatry 2009, 66:84-90. 
38. Monteggia LM, Luikart B, Barrot M, Theobold D, Malkovska I, Nef S, Parada $L F$, Nestler EJ: Brain-derived neurotrophic factor conditional knockouts show gender differences in depression-related behaviors. Biol Psychiatry 2007, 61:187-197.

39. Cazorla M, Prémont J, Mann A, Girard N, Kellendonk C, Rognan D: Identification of a low-molecular weight TrkB antagonist with anxiolytic and antidepressant activity in mice. J Clin Invest 2011, 121:1846-1857.

40. Cunningham ST, Kelley AE: Hyperactivity and sensitization to psychostimulants following cholera toxin infusion into the nucleus accumbens. J Neurosci 1993, 13:2342-2350.

41. Everitt BJ, Robbins TW: Neural systems of reinforcement for drug addiction: from actions to habits to compulsion. Nat Neurosci 2005, 8:1481-1489.

42. Beeler JA, Cao ZF, Kheirbek MA, Zhuang X: Loss of cocaine locomotor response in Pitx3-deficient mice lacking a nigrostriatal pathway. Neuropsychopharmacology 2009, 34:1149-1161.

43. Everitt BJ, Robbins TW: From the ventral to the dorsal striatum: devolving views of their roles in drug addiction. Neurosci Biobehav Rev 2013. e-pub ahead of print 21 February 2013; doi: 10.1016/j.neubiorev.2013.02.010.

44. Hollander JA, Im HI, Amelio AL, Kocerha J, Bali P, Lu Q, Willoughby D, Wahlestedt C, Conkright MD, Kenny PJ: Striatal microRNA controls cocaine intake through CREB signalling. Nature 2010, 466:197-202.

45. Im HI, Hollander JA, Bali P, Kenny PJ: MeCP2 controls BDNF expression and cocaine intake through homeostatic interactions with microRNA-212. Nat Neurosci 2010, 13:1120-1127.

46. Berton O, McClung CA, Dileone RJ, Krishnan V, Renthal W, Russo SJ, Graham D, Tsankova NM, Bolanos CA, Rios M, Monteggia LM, Self DW, Nestler EJ: Essential role of BDNF in the mesolimbic dopamine pathway in social defeat stress. Science 2006, 311:864-8.

47. Abarca C, Albrecht U, Spanagel R: Cocaine sensitization and reward are under the influence of circadian genes and rhythm. Proc Natl Acad SCl U S A 2002, 99:9026-9030.

48. Thakker-Varia S, Alder J: Neuropeptides in depression: role of VGF. Behav Brain Res 2009, 197:262-278.

49. Chen X, Grisham W, Arnold AP: X chromosome number causes sex differences in gene expression in adult mouse striatum. Eur $J$ Neurosci 2009, 29:768-776.

50. Reinius B, Shi C, Hengshuo L, Sandhu KS, Radomska KJ, Rosen GD, Lu L, Kullander K, Williams RW, Jazin E: Female-biased expression of long non-coding RNAs in domains that escape X-inactivation in mouse. BMC Genomics 2010, 11:614.

51. Lynch WJ, Kiraly DD, Caldarone BJ, Picciotto MR, Taylor JR: Effect of cocaine self-administration on striatal PKA-regulated signaling in male and female rats. Psychopharmacology (Berl) 2007, 191:263-271.

52. Sunal R, Gümüşel B, Kayaalp SO: Effect of changes in swimming area on results of "behavioral despair test". Pharmacol Biochem Behav 1994, 49:891-896.

53. Willuhn I, Sun W, Steiner H: Topography of cocaine-induced gene regulation in the rat striatum: relationship to cortical inputs and role of behavioural context. Eur J Neurosci 2003, 17:1053-66.

54. Franklin KBJ, Paxinos G: The Mouse Brain in Stereotaxic Coordinates. New York: Academic Press; 1997

55. Smyth GK: linear models for microarray data. In Bioinformatics and Computational Biology Solutions using R and Bioconductor. Edited by Gentleman R, Carey VJ, Huber W, Irizarry R, Dudoit S. New York: Springer; 2005:397-420.

doi:10.1186/1750-1326-8-47

Cite this article as: Unterwald et al:: Behavioral and transcriptome alterations in male and female mice with postnatal deletion of TrkB in dorsal striatal medium spiny neurons. Molecular Neurodegeneration 2013 8:47.

\section{Submit your next manuscript to BioMed Central and take full advantage of:}

- Convenient online submission

- Thorough peer review

- No space constraints or color figure charges

- Immediate publication on acceptance

- Inclusion in PubMed, CAS, Scopus and Google Scholar

- Research which is freely available for redistribution

Submit your manuscript at www.biomedcentral.com/submit 